\title{
Qualidade Sanitária e Fisiológica de Sementes de Abóbora Variedade Menina Brasileira*
}

\author{
Derblai Casaroli' ${ }^{1}$, Danton C. Garcia ${ }^{1}$, Marlove F. B. Muniz ${ }^{2} \&$ Nilson L. de Menezes ${ }^{1}$ \\ ${ }^{1}$ Departamento de Fitotecnia; ${ }^{2}$ Departamento de Defesa Fitossanitária, Universidade Federal de Santa Maria, \\ CEP 97105-900, Santa Maria, RS, e-mail: casaroli@esalq.usp.br
}

(Aceito para publicação em 19/07/2005)

Autor para correspondência: Derblai Casaroli

CASAROLI, D., GARCIA, D.C., MUNIZ, M.F.B \& MENEZES, N.L. Qualidade sanitária e fisiológica de sementes de abóbora variedade Menina Brasileira. Fitopatologia Brasileira 31:158-163. 2006.

\begin{abstract}
RESUMO
O trabalho teve como objetivos avaliar e correlacionar a qualidade sanitária e fisiológica de sementes de abóbora, variedade Menina Brasileira (Cucurbita moschata.). Foram avaliados dois lotes de sementes de abóbora produzidas no sistema agroecológico e quatro no sistema convencional, com e sem tratamento químico. Os lotes foram submetidos aos testes de sanidade, seguindo a metodologia do "Blotter test", com congelamento, germinação e vigor (primeira contagem, índice de velocidade de germinação, envelhecimento acelerado e emergência de plântulas). Os resultados indicaram a separação dos lotes de diferentes origens a partir da qualidade sanitária e fisiológica, onde as maiores incidências de fungos foram observadas nos lotes agroecológicos e o maior potencial fisiológico foi observado nos lotes de origem convencional não tratados. Foram encontrados os fungos Fusarium oxysporum, Alternaria alternata, Cladosporium cucumerinum, Aspergillus niger, Penicillium digitatum, Rhizopus stolonifer e Phoma terrestris. A qualidade sanitária não interferiu na qualidade fisiológica das sementes de abóbora, variedade Menina Brasileira.

Palavras-chaves adicionais: Cucurbita moschata, sistema agroecológico e convencional, potencial fisiológico, fungos.

ABSTRACT

Health and Physiological Quality of 'Menina Brasileira' Squash Seeds

The objective of this work was to evaluate and correlate the health and physiological qualities of squash seeds of the variety Menina Brasileira (Cucurbita moschata.). We evaluated two squash seed lots produced in the agroecological system and four seed lots produced in the conventional system with and without chemical treatment. The seed lots were submitted to health tests with freezing, germination and vigour, following Blotter test methodology (first count, germination speed, accelerated ageing and seedling emergence tests). The results from the health and physiological tests indicated a difference between seed lots from different origins: the agroecological lots showed the highest incidence of fungi and the conventional lots without chemical treatment showed the highest physiological potential. The fungi Fusarium oxysporum, Alternaria alternata, Cladosporium cucumerinum, Aspergillus niger, Penicillium digitatum, Rhizopus stolonifer and Phoma terrestris were found to be associated with seeds. The health quality did not interfere with the physiological quality of the 'Menina Brasileira' squash seeds.
\end{abstract}

Additional keywords: Cucurbita moschata, agroecological system, physiological potential, fungi.

\section{INTRODUÇÃO}

A presença de patógenos nas sementes, independentemente de sua transmissibilidade, pode afetar o vigor e o rendimento em campo (Zorato \& Henning, 2001; Luz, 2003). Esse efeito é mais pronunciado quando se trata de organismos que colonizam os tecidos das sementes. Por outro lado, a redução do vigor decorrente de fatores não infecciosos pode predispor essas estruturas à ação mais severa de patógenos (Machado, 1994; Menten, 1995). Assim, o uso de sementes com menor vigor pode ter reflexos

\footnotetext{
*Parte da Dissertação de Mestrado do primeiro autor. Universidade Federal de Santa Maria. 2005.
}

negativos dos mais variáveis, considerando-se não somente um menor desempenho das plantas em termos de estande como, também, a maior vulnerabilidade dessas sementes ao ataque de patógenos. Por tudo isto, tem-se recomendado uma integração entre os testes de sanidade e qualidade fisiológica de sementes (Neergaard, 1979; Menten, 1995).

Machado (1994) relatou que danos decorrentes da associação dos patógenos com as sementes não se limitam a perdas diretas da população em campo, mas envolvem outras implicações que podem provocar sérios danos em todo o sistema de produção. Para um grande número de doenças, as sementes portadoras de seus agentes causais constituem sua única forma de perpetuação e disseminação na natureza.

Ao avaliar a qualidade sanitária e fisiológica de 
sementes, pode-se obter reflexos positivos ou negativos quanto à produção. $\mathrm{O}$ conhecimento do potencial fisiológico das sementes permite, principalmente, para espécies onde ocorre transplante de mudas, que estas sejam de tamanho e qualidade uniformes, com reflexos no desenvolvimento das plantas e, possivelmente, na produção final. Portanto, a produção de mudas e de plantas sadias depende em grande parte da utilização de sementes de boa qualidade (Marcos Filho, 2001).

Assim, o tratamento de sementes com produtos químicos, principalmente fungicidas, é considerado uma prática usual e eficiente para aumento da produção (Reis \& Forcelini, 1994). Porém, quando se busca a produção de alimentos sem a utilização de produtos químicos, como é o caso do sistema de produção agroecológica, deve-se incluir as sementes neste contexto, por serem o insumo básico de qualquer atividade de cultivo.

São poucos os relatos de pesquisas realizadas no Brasil sobre a avaliação da qualidade de sementes de abóbora, especialmente, com sementes produzidas em sistemas agroecológicos, as quais têm demonstrado boa qualidade fisiológica, com uma grande vantagem, não são utilizados produtos químicos em seu sistema produtivo (Nascimento, 2004). Sendo assim, a realização de trabalhos visando primeiramente qualificar e quantificar problemas fitossanitários é de grande importância, principalmente, quando se pensa em produção de hortaliças sem o uso de produtos químicos.

O objetivo do trabalho foi avaliar e correlacionar a qualidade sanitária e fisiológica de sementes de abóbora (Cucurbita moschata Duch.), produzidas em três sistemas.

\section{MATERIAL E MÉTODOS}

A pesquisa foi desenvolvida no Laboratório de Patologia de Sementes do Departamento de Defesa Fitossanitária, no Núcleo de Pesquisa em Ecofisiologia e Hidroponia e no Laboratório Didático e de Pesquisa em Sementes do Departamento de Fitotecnia da Universidade Federal de Santa Maria (UFSM), Santa Maria RS.

Foram utilizados dois lotes de sementes de abóbora variedade Menina Brasileira, produzidos em sistema Agroecológico, sem qualquer utilização de substâncias consideradas tóxicas para seres humanos, animais e meio ambiente e quatro lotes produzidos em sistema Convencional, sendo dois lotes tratados com fungicidas Thiram $45 \%$ (5 ml $\mathrm{Kg}^{-1}$ ) e Captan-75 a 0,2\% e dois não tratados.

As sementes foram submetidas as seguintes análises: a) determinação do teor de água (TAS) - conduzido em estufa a $105 \pm 3{ }^{\circ} \mathrm{C}$ por 24 horas, utilizando-se duas subamostras por lote com aproximadamente $5 \mathrm{~g}$ de sementes, conforme as Regras para Análise de Sementes (Brasil, 1992); b) teste de sanidade - utilizou-se a metodologia do papel filtro ou "Blotter test" com congelamento. Foram utilizadas oito repetições de 25 sementes, colocadas em caixas plásticas do tipo "gerbox" contendo três folhas de papel filtro umedecidos com água destilada em uma proporção de 2,5 vezes o peso do papel seco. As sementes foram incubadas à temperatura de $25{ }^{\circ} \mathrm{C}$ por sete dias, sob fotoperíodo de 12 horas de regime de luz e 12 horas de escuro. Após o período de incubação as sementes foram examinadas individualmente sob microscópio estereoscópio e microscópio óptico, computando-se a percentagem de incidência, sendo realizada a identificação dos patógenos com base em suas características morfológicas (Barnett \& Hunter, 1972); c) teste de germinação (TG) - realizado com oito repetições de 50 sementes, sobre papel filtro umedecido com água destilada na proporção de 2,5 vezes o peso do papel seco. As sementes foram colocadas em germinador a $25^{\circ} \mathrm{C}$ e as contagens de plântulas normais foram efetuadas aos quatro e oito dias após a semeadura (Brasil, 1992); d) primeira contagem (PC) - realizada conjuntamente com o teste de germinação, constituindo o registro da percentagem de plântulas normais verificadas na primeira contagem do teste de germinação (Brasil, 1992), realizada no quarto dia após a semeadura; e) índice de velocidade de germinação (IVG) - seguiu-se a mesma metodologia do teste de germinação. As sementes foram colocadas em germinador a $25^{\circ} \mathrm{C}$, onde foram realizadas avaliações diárias, à mesma hora, a partir do dia em que surgiram as primeiras sementes consideradas germinadas (raiz primária visível) permanecendo até a estabilização. Ao fim do teste, com os dados diários do número de sementes germinadas por repetição, calculou-se o índice de velocidade de germinação, conforme Maguire (1962); f) envelhecimento acelerado (EA) - conduzido em caixas plásticas do tipo "gerbox" (AOSA, 1983). Utilizaram-se amostras de aproximadamente $20 \mathrm{~g}$ divididas em duas subamostras. Cada subamostra foi distribuída uniformemente de maneira a formar uma camada simples sobre a superfície de tela metálica suspensa no interior da caixa, as quais continham $40 \mathrm{ml}$ de água destilada ao fundo. As caixas tampadas foram levadas à incubadora, onde permaneceram à temperatura de $41^{\circ} \mathrm{C}$, por 48 horas. Ao término desse período as sementes foram colocadas para germinar, conforme a metodologia do teste de germinação descrita anteriormente, efetuando-se uma única contagem no sexto dia após a semeadura; g) emergência de plântulas (EM) - foram utilizadas quatro repetições de 50 sementes, com semeadura em bandejas de isopor com 128 células, contendo substrato organo-mineral e mantidas em condições de ambiente parcialmente controlado (estufa plástica), em piscina hidropônica sobre solução nutritiva diluída a $50 \%$, conforme Castellane \& Araujo (1994). As análises foram realizadas aos sete dias após a semeadura.

$\mathrm{O}$ delineamento experimental utilizado foi $\mathrm{o}$ inteiramente casualizado, onde os tratamentos constituíramse em número de três, representando as origens das sementes, com quatro repetições. Foi realizada a análise da variância e as médias comparadas pelo teste de Tukey ao nível de $5 \%$ de probabilidade. Entre as médias dos lotes de mesma origem, utilizou-se o teste $\mathrm{t}$ (student) a $5 \%$ de probabilidade. Os dados também foram submetidos ao teste de correlação 
simples de Pearson (r), exceto para os fungos Aspergillus niger Tiegh., Cladosporium cucumerinum Ellis \& Arthur e Phoma terrestris H.N. Hansen. Os dados expressos em percentagem foram transformados para arco seno $(\mathrm{x} / 100)^{1 / 2}$ e as variáveis com algum valor igual a zero tiveram seus dados transformados para $\mathrm{y}=\mathrm{x}+0,01$.

\section{RESULTADOS E DISCUSSÃO}

\section{Qualidade Sanitária}

Conforme apresentado na Tabela 1, são observadas diferenças significativas, para o total de fungos e, individualmente, para a maioria dos fungos detectados na avaliação da qualidade sanitária das sementes de abóbora quanto aos sistemas e entre lotes dentro de um mesmo sistema. As maiores incidências de fungos ocorreram nas sementes dos sistemas agroecológico e convencional não tratadas, mostrando diferenças significativas em relação aos lotes provenientes de sistema convencional tratados, comprovando assim, a eficácia dos produtos químicos utilizados. $\mathrm{O}$ uso de produtos químicos tem por objetivo o controle de microorganismos associados às sementes e a proteção das mesmas e das plântulas contra a ação de microorganismos do solo, contribuindo para a redução da transmissão de patógenos para a parte aérea das plantas (Luz, 2003).

As sementes provenientes do sistema agroecológico apresentaram as maiores incidências para a maioria dos fungos encontrados. Desta forma, entende-se, que sementes dessa origem devem receber algum tratamento alternativo, como controle biológico (Vidhyasekaran \& Muthamilan,
1995). Sementes produzidas em sistemas agroecológico e orgânicos, os quais não utilizam produtos químicos em nenhuma das etapas de produção, são facilmente infestadas por fungos, tornando a qualidade sanitária um motivo de preocupação durante toda a fase de produção (Nascimento, 2004). Devido à infestação nas sementes agroecológicas, Casaroli et al. (2003) observaram a interferência negativa na germinação e emergência de plântulas de abóbora, variedade Menina Brasileira.

Para o fungo Fusarium oxysporum, as diferenças significativas foram observadas apenas entre lotes com e sem tratamento químico e entre os lotes do sistema agroecológico, portanto, demonstrando uma variação entre lotes provenientes do mesmo sistema de produção. Esse fungo é um importante patógeno das culturas do melão e melancia, por causar murchas vasculares e tombamento de plântulas em suas formas Fusarium oxysporum f. sp. melonis e Fusarium oxysporum f. sp. niveum, respectivamente (Rego, 1995; Zitter et al., 1996). Também podem atacar raízes e colo das plantas, causando apodrecimento dos tecidos, em melancia e melão, sendo mais severo em abóbora e abobrinha, na forma de Fusarium solani f. sp. cucurbitae (Rego, 1995; Zitter et al., 1996), tendo nas sementes seu principal veículo de disseminação e sobrevivência.

Também para os fungos Alternaria alternata e Cladosporium cucumerinum, os lotes dos três sistemas apresentaram diferenças significativas quanto a incidência desses patógenos. As maiores médias de A. alternata foram observadas nos lotes do sistema convencional não tratados, enquanto para C. cucumerinum foram detectadas diferenças

TABELA 1. Percentagens médias referentes a incidência de Fusarium oxysporum (FUS), Alternaria alternata (ALT), Cladosporium cucumerinum (CLAD), Aspergillus niger (ASP), Penicillium digitatum (PEN), Rhizopus stolonifer (RHIZ) e Phoma terrestris (PHO) e total de fungos presentes (TF), em lotes de sementes de abóbora, variedade Menina Brasileira, provenientes de três sistemas.

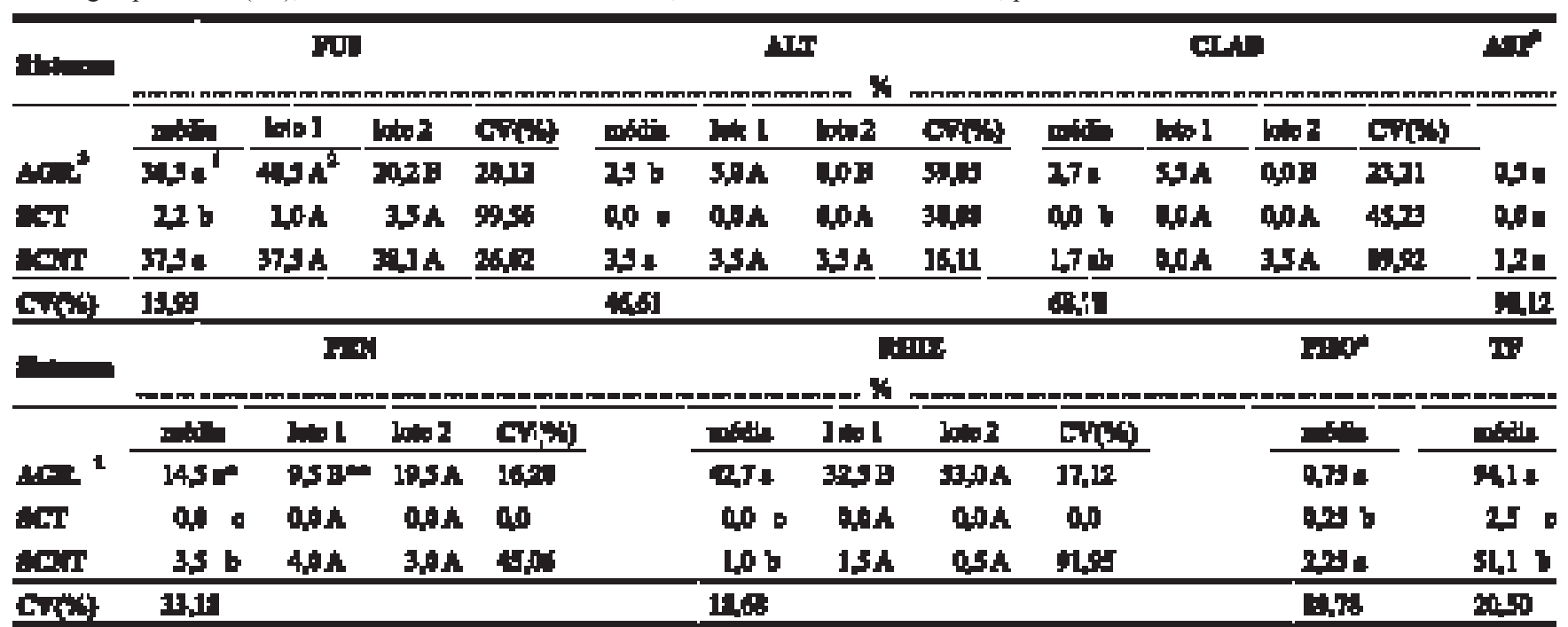

${ }^{1}$ Médias seguidas pela mesma letra minúscula na coluna, não diferem entre si pelo teste de Tukey, ao nível de 5\% de probabilidade;

${ }^{2}$ Médias seguidas pela mesma letra maiúscula na linha, não diferem entre si pelo teste t (student), ao nível de 5\% de probabilidade;

${ }^{3}$ AGR.$=$ Sistema Agroecológico; $\mathrm{SCT}=$ Sistema convencional tratado; $\mathrm{SCNT}=$ Sistema convencional não tratado;

*Não houve interação significativa entre os lotes oriundos do mesmo sistema de produção. 
apenas entre os lotes de origem agroecológico e convencional tratados, onde, novamente, os lotes do sistema agroecológico mostraram as maiores percentagens de infestação. Manchas foliares causadas por C. cucumerina são comuns em plantas de melão, ocorrendo com menor severidade em abóbora, melancia, pepino e chuchu, podendo sobreviver nas sementes (Rego, 1995; Zitter et al., 1996). Também pode-se encontrar manchas necróticas nas folhas de pepino, melão e melancia, causadas por A. alternata f. sp. cucurbitae (Zitter et al., 1996). O fungo C. cucumerinum é o agente causal da Sarna, importante doença das Cucurbitáceas, causando lesões nas folhas, pecíolos, caules e frutos de plantas de abóbora, abobrinha, melão e melancia, sendo mais severo em pepino (Rego, 1995; Zitter et al., 1996).

Com relação à incidência de Aspergillus niger, fungo de armazenamento, causador de podridões em sementes (Menten, 1995; Zitter et al., 1996), não foram observadas interações significativas entre lotes do mesmo sistema produtivo, nem entre as médias dos diferentes sistemas. Por outro lado, com referência ao Penicillium digitatum (Pers.) Sacc. observaram-se diferenças significativas entre os sistemas quanto à presença desse fungo, o qual foi mais freqüente nas sementes produzidas no sistema agroecológico, havendo também, diferenças entre os lotes dessas sementes. Nos lotes de sementes produzidos em sistema convencional não tratados, as incidências foram significativamente menores em relação aos lotes agroecológicos, enquanto nos lotes do sistema convencional tratados, a incidência foi zero. As espécies desse gênero são considerados fungos típicos de armazenamento, podendo ocasionar apodrecimento das sementes, não sendo, porém, transmitido para as plântulas e plantas (Zitter et al., 1996). Penicillium digitatum Sacc. pode promover podridões em frutos (Rego, 1995).

A espécie Rhizopus stolonifer (Ehrenb.) Vuill. mostrou a maior média de incidência nos lotes do sistema agroecológico e a menor nos lotes do sistema convencional tratados. Essa espécie pode causar podridões de sementes e plântulas de algodão, atacando os cotilédones, apodrecendoos antes da emergência, quando apenas o sistema radicular foi emitido, progredindo posteriormente, para toda plântula (Menten, 1995). Podridões moles nos tecidos de Cucurbitáceas também podem ser causadas pelo fungo $R$. stolonifer ( $\mathrm{Fr}$.) Lind., afetando geralmente os frutos (Rego, 1995; Zitter et al., 1996). Entretanto, ao tratar-se de sementes, o gênero Rhizopus é considerado, geralmente, um contaminante (Rego, 1995). O fungo P. terrestris foi detectado em sementes oriundas dos três sistemas, porém com baixa incidência, observando-se o menor percentual no sistema convencional tratado. Essa espécie pode causar lesões de coloração rosa tendendo ao vermelho, encontradas nas raízes das Cucurbitáceas, facilitando a entrada de outros organismos (Zitter et al., 1996).

Diferenças significativas também foram observadas para o total de fungos infestando as sementes, verificando-se a separação das origens em três grupos de acordo com a sua qualidade sanitária, onde as maiores médias foram obtidas nos lotes do sistema agroecológico apresentando a menor qualidade sanitária, seguidos pelos lotes provenientes dos sistemas convencionais não tratados e tratados (Tabela 1).

\section{Qualidade Fisiológica}

$\mathrm{Na}$ avaliação da qualidade fisiológica, por meio dos testes de germinação e vigor (Tabela 2), os maiores valores de potencial fisiológico foram obtidos nas sementes dos lotes provenientes do sistema convencional não tratados. No teste de germinação detectaram-se diferenças quanto aos sistemas, mas não entre lotes do mesmo sistema. Alguns autores também observaram a estratificação de lotes de sementes de abobrinha (Cucurbita pepo) e abobrinha cv. Piramoita, respectivamente, em diferentes níveis de qualidade fisiológica a partir do teste de germinação (Barros et al., 2002; Cardoso, 2003).

Nos testes de vigor avaliados detectaram-se diferenças significativas entre lotes de diferentes sistemas, observandose maior sensibilidade para a estratificação dos lotes em função do potencial fisiológico, nos testes de primeira contagem e envelhecimento acelerado, onde ocorreram níveis maiores, menores e intermediários de vigor das sementes

TABELA 2. Dados médios dos testes de germinação (TG), primeira contagem (PC), índice de velocidade de germinação (IVG), envelhecimento acelerado (EA) e emergência de plântulas (EM), de lotes de sementes de abóbora, variedade Menina Brasileira, provenientes de três diferentes sistemas. Santa Maria, RS, 2004

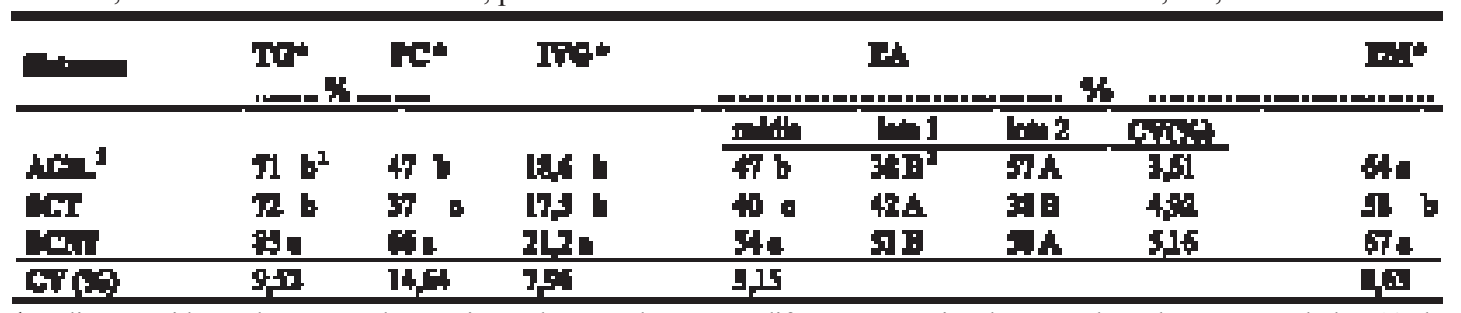

${ }^{1}$ Médias seguidas pela mesma letra minúscula na coluna, não diferem entre si pelo teste de Tukey, ao nível de 5\% de probabilidade.

${ }^{2}$ Médias seguidas pela mesma letra maiúscula na linha, não diferem entre si pelo teste de $\mathrm{t}$ (student), ao nível de $5 \%$ de probabilidade.

${ }^{3} \mathrm{AGR} .=$ Sistema Agroecológico; $\mathrm{SCT}=$ Sistema convencional tratado; $\mathrm{SCNT}=$ Sistema convencional não tratado.

*Não houve interação significativa entre os lotes oriundos do mesmo sistema de produção. 
(Tabela 2). O teste de primeira contagem pode ser utilizado rotineiramente para se obter informações complementares sobre o vigor de lotes de sementes de pepino e alface, respectivamente (Bhering et al., 2000; Franzin, 2003). Esse teste avalia indiretamente a velocidade de germinação das sementes Nakagawa (1999) indica que a primeira contagem, muitas vezes, expressa melhor as diferenças de velocidade de germinação entre lotes, que os índices de velocidade de germinação (IVG).

$\mathrm{O}$ teste de envelhecimento acelerado mostrou eficiência também, para detecção de diferentes potenciais fisiológico das sementes entre lotes de mesmo sistema. Bhering et al. (2000) e Barros et al. (2002) também comprovaram a eficiência do período de 48 horas de exposição ao estresse à temperatura de $41{ }^{\circ} \mathrm{C}$, para estratificação de lotes de sementes de pepino e abobrinha, respectivamente.

Para Cardoso (2003), os dados de emergência das sementes de abobrinha cv. Piramoita apontaram apenas o lote de maior vigor, sendo que os outros lotes avaliados não diferiram e foram considerados de menor vigor. Entretanto, esse autor avaliou a emergência aos 21 dias após a semeadura, não observando diferenças entre lotes.

As espécies encontradas no presente trabalho podem ser divididas em fungos que são transmitidos às plântulas e plantas via semente, como Fusarium oxysporum, Alternaria alternata e Cladosporium cucumerinum, e fungos de armazenamento, onde se enquadram as demais espécies detectadas nas sementes de abóbora, exceto Rhizopus, tratado como um contaminante.

As médias obtidas pelos gêneros de fungos de campo, com potencial de transmissão, foram maiores que as médias dos fungos de armazenamento (Tabela 1). Talvez por isso, os lotes provenientes de sistema convencional não tratados expressaram seu vigor sem interferências negativas em função da presença de fungos. As maiores incidências nesses lotes foram dos fungos que são transmitidos via semente, ocasionando, principalmente, "damping-off" ou tombamento de plântulas (Machado, 1988; Menten, 1995), o mesmo não foi observado na emergência de plântulas (Tabela 2), os quais apresentaram as maiores médias, diferindo significativamente dos lotes de menor percentagem de emergência. Isso pode ser explicado, devido às plântulas terem sido produzidas em sistema hidropônico, em condições mais favoráveis de nutrição, favorecendo o seu desenvolvimento e diminuindo a ação de organismos patogênicos.

Considerando que a maioria das espécies de fungos patogênicas necessitam de alta temperatura e umidade para seu melhor desenvolvimento (Neergaard, 1979), observaram-se coeficientes de correlação positivos e significativos a $1 \%$, para os fungos Fusarium oxysporum $(\mathrm{r}=0,86)$, Alternaria alternata $(\mathrm{r}=0,48)$ e Penicillium digitatum $(\mathrm{r}=0,61)$ e total de incidência de fungos $(\mathrm{r}=$ $0,88)$ em relação ao teor de água das sementes, proveniente das análises de caracterização dos lotes, a qual apresentou variações de $6,6 \%, 8,2 \%$ e $8,4 \%$, para os lotes convencionais tratados, não tratados e agroecológicos, respectivamente. As mesmas espécies foram correlacionadas com os testes, as quais avaliaram a qualidade fisiológica das sementes, observando-se, no entanto, que os coeficientes de correlação entre a presença das diferentes espécies fúngicas e os testes de qualidade fisiológica foram, de modo geral, positivos e não significativos. Deve-se observar, principalmente, os coeficientes negativos e significativos, pois estes podem mostrar a interferência negativa da presença de patógenos sobre a qualidade fisiológica das sementes, o que não ocorreu no presente estudo.

Alguns autores verificaram que certos fungos, ao infectarem as sementes, danificam suas estruturas celulares de modo a prejudicar sua viabilidade, podendo até ocasionar a morte da mesma (Wetzel, 1987; Machado, 1988; Menten, 1995). Pesquisas relacionando o nível de incidência de fungos e qualidade fisiológica das sementes de hortaliças mostraram interferência negativa, como exemplo, Alternaria sp. em sementes de cenoura (Muniz \& Porto, 1999). Entretanto, outros autores observaram que a presença de fungos e bactérias não afetaram de forma negativa a qualidade fisiológica de sementes de tomate (Torres et al., 1999). Por outro lado, Dias \& Toledo (1993) constataram que a incidência de fungos em sementes de braquiária reduziu a sua germinação, porém Bevilaqua \& Pierobom (1995) observaram, que sementes de aveia preta apresentaram alto vigor mesmo estando infestadas com fungos dos gêneros Fusarium, Alternaria e Phoma. Portanto, muitas vezes os resultados são divergentes, pois trabalha-se com organismos vivos, os quais dependem da associação de fatores intrínsecos e extrínsecos na expressão do efeito causado.

Neste trabalho foi evidenciado que os fungos detectados nas sementes de abóbora variedade Menina Brasileira, não interferiram na sua qualidade fisiológica, como pode ser observado também pela análise de correlação. Entretanto, o potencial fisiológico foi afetado por fatores tais como o sistema, o tratamento químico e a qualidade inicial dos lotes. Os lotes de sistema agroecológico mostraram a menor qualidade sanitária e os lotes de sistema convencional não tratados apresentaram o maior vigor.

\section{REFERÊNCIAS BIBLIOGRÁFICAS}

ASSOCIATION OF OFFICIAL SEED ANALYSTS - AOSA. Seed vigour testing handbook. Lincoln. 1983. 93 p. (Contribution, 32).

BARNETT, H.L. \& HUNTER, B.B. Illustrated genera of imperfect fungi. $3^{\text {rd }}$ ed. Minneapolis MN. Burgess Publishing Company. 1972.

BARROS, D.I., NUNES, H.V., DIAS, D.C.F.S. \& BHERING, M. C. Comparação entre testes de vigor para avaliação da qualidade fisiológica de sementes de tomate. Revista Brasileira de Sementes 24:12-16. 2002.

BARROS, D.I., DIAS, D.C.F.S., BHERING, M.C., DIAS, L.A. S. \& PUIATTI, M. Avaliação do vigor de sementes de abobrinha 
(Cucurbita pepo) pelo teste de tetrazólio. Horticultura Brasileira 20. 2002. Suplemento 2. (CD-ROM).

BEVILAQUA, G.A. . \& PIEROBOM, C.R. Qualidade sanitária e fisiológica de sementes de aveia preta (Avena strigosa Schreb.) da zona sul do Rio Grande do Sul. Revista Brasileira de Sementes 17:19-22. 1995.

BHERING, M.C, DIAS, D.C.F. ., GOMES, J.M. \& BARROS, D.I. Métodos para avaliação do vigor de sementes de pepino. Revista Brasileira de Sementes 22:171-175. 2000.

BRASIL. Ministério da Agricultura e Reforma Agrária. Regras para Análise de Sementes. Brasília:SNAD/DNDV/CLAV. 1992.

CARDOSO, A. I. I. Produção e qualidade de sementes de abobrinha "Piramoita" em resposta à quantidade de pólen. Bragantia 62:4752. 2003.

CASAROLI, D, MUNIZ, M.F.B, DUTRA, D, SILVA, M.A.S. da \& GARCIA, D. C. Avaliação da qualidade de sementes de abóbora variedade Menina Brasileira, produzidas pelo sistema agroecológico. Anais, I. Congresso Brasileiro de Agroecologia, IV. Seminário Internacional sobre Agroecologia e V. Seminário Estadual sobre Agroecologia. Porto Alegre RS. 2003. (CD-ROM)

CASTEllane, D.P. \& ARAUJO, J.A. C. Cultivos sem Solo hidroponia. Jaboticabal SP. Universidade Estadual Paulista. 1994.

DIAS, D.C.F. \& TOLEDO, F.F. Germinação e incidência de fungos em testes com sementes de Brachiaria decumbens. Revista Brasileira de Sementes 15:81-86. 1993.

FRANZIN, S.M. Qualidade fisiológica de sementes de alface - Métodos para determinação e relação com a formação de mudas. (Dissertação de Mestrado). Santa Maria RS. Universidade Federal de Santa Maria. 2003.

LUZ, W.C. da. Combinação dos tratamentos biológico e químico de sementes de milho. Fitopatologia Brasileira 28:37-40. 2003.

MACHADO, J.C. Patologia de sementes: fundamentos e aplicações. Lavras MG. ESAL/FAEPE. 1988.

MACHADO, J.C. Padrões de tolerância de patógenos associados a sementes. Revisão Anual de Patologia de Plantas 2:229-263. 1994.

MAGUIRE, J.D. Spead of germination-aid in selection and evaluation for seedling emergence and vigour. Crop Science 2:176177. 1962.
MARCOS FILHO, J. Pesquisa sobre vigor de sementes de hortaliças. Informativo ABRATES 11:63-75. 2001.

MENTEN, J.O.M. Patógenos em sementes: detecção, danos e controle químico. São Paulo SP. CibaAgro. 1995.

MUNIZ, M.F.B. \& PORTO, M.D.M. Presença de Alternaria spp. em diferentes partes da semente de cenoura e em resíduos culturais e efeito do tratamento de sementes na sua transmissão. Revista Brasileira de Sementes 21:187-193. 1999.

NAKAGAWA, J. Testes de vigor baseados no desempenho das plântulas. In: Krzyzanowski, F.C., Vieira, R.D. \& França Neto, J.B (Eds.) Vigor de sementes:conceitos e testes. Londrina PR. ABRATES. 1999. pp. 21-24.

NASCIMENTO, W.M. Sementes orgânicas de hortaliças constituem um novo nicho de mercado. Seed News Ano VIII:26-27. 2004.

NEERGAARD, P. Seed Pathology. London. Mac Millan Press. 1979.

REGO, A.M. Doenças causadas por fungos em Cucurbitáceas. Informe Agropecuário 17:48-54. 1995.

REIS, E.M. \& FORCELINI, C.A. Manual de fungicidas: guia para o controle de doenças. Passo Fundo RS. Pe. Berthier. 1994.

TORRES, S.B., PEIXOTO, A.R. \& CARVALHO, I.M.S. Qualidade sanitária e fisiológica de sementes de tomate da região do submédio São Francisco. Ciência e Agrotécnica 23:825-829. 1999.

VIDHYASEKARAN, P. \& MUTHAMILAN, M. Development of formulations of Pseudomonas fluorescens for control of chickpea wilt. Plant Disease 79:782-786. 1995.

WETZEL, M.M.V.S. Fungos de armazenamento. In: Soave, J. \& Wetzel, M.M.V.S. (Eds.) Patologia de sementes. Campinas SP. Fundação Cargill. 1987. pp. 260-275.

ZITTER, T.A., HOPKINS, D.L. \& THOMAS, C.E. Compendium of cucurbit diseases. Saint Paul MN. American Phytopathological Society. 1996.

ZORATO, M.F. \& HENNING, A.A. Influência de tratamentos com fungicidas antecipados, aplicados em diferentes épocas de armazenamento, sobre a qualidade de sementes de soja. Revista Brasileira de Sementes 23:236-244. 2001. 